\title{
CORNEAL PERFORATION AS A COMPLICATION OF EPIDERMOLYSIS BULLOSA ACQUISITA
}

\author{
W. A. ACLIMANDOS \\ London
}

\begin{abstract}
SUMMARY
Epidermolysis bullosa acquisita (EBA) is now recognised as a histopathologically distinct condition. ${ }^{1-3}$ Ocular complications of hereditary epidermolysis bullosa (EB) have been well documented, ${ }^{4}$ but little has been reported with respect to the ocular manifestations associated with the acquired form..$^{5-8}$

$A$ patient with EBA and sarcoidosis - an association that does not appear to have been previously reported - developed spontaneous peripheral corneal melting and perforation. The defect healed with the use of a bandage contact lens, antibiotics, mydriatics and pulsed intravenous steroids, and resulted in a satisfactory visual outcome.
\end{abstract}

\section{CASE REPORT}

A 38-year-old Jamaican woman with sarcoidosis and EBA presented with a short history of intermittent episodes of grittiness and redness of both eyes associated with reduced vision. She was myopic

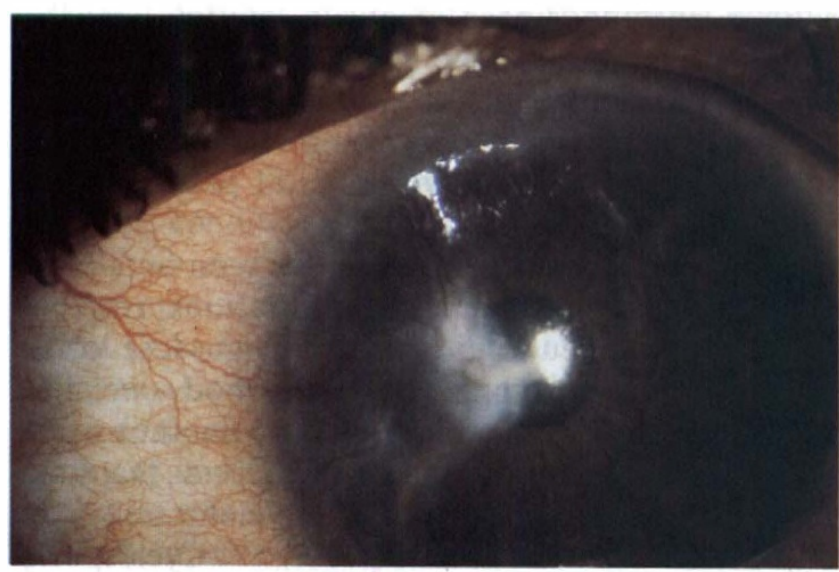

Fig. 1. Healed corneal perforation with pigmentation at site of previous iris 'plugging'.

Corrspondence to: W. A. Aclimandos, FRCS, FRCOphth, Eye Department, King's College Hospital, Denmark Hill, London SE5 9RS, UK. with previously normal corrected visual acuity. She had been treated for one episode of anterior uveitis 8 years earlier.

Sarcoidosis had been confirmed by liver biopsy and raised serum angiotensin converting enzyme (ACE) levels, while the diagnosis of EBA was made on the basis of the clinical presentation and a split skin biopsy. Systemic steroids had previously been used for treatment of her sarcoidosis but had to be stopped because of significant weight gain and depression. A course of dapsone was subsequently tried for her skin condition but proved to be of no benefit. Her condition was well controlled with oral azathioprine $250 \mathrm{mg}$ daily.

On examination there was no sign of blepharitis. The tear film was reduced and there was marked diffuse punctate conjunctival and corneal epithelial erosions but no significant conjunctival scarring. She had $360^{\circ}$ of peripheral corneal vascularisation of about 1-2 $\mathrm{mm}$. She also had a mild degree of episcleral injection. These changes were almost symmetrical in both eyes. During the following 5 months the visual acuity fluctuated in both eyes from $6 / 6$ to $6 / 36$ in accordance with the corneal changes and the amount of mucus in her tear film. The

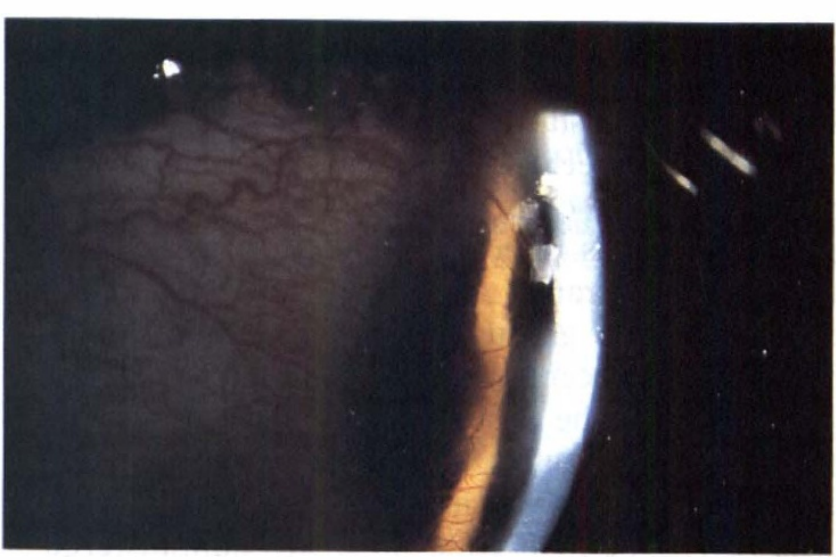

Fig. 2. Slit view of healed corneal perforation.

Eye (1995) 9, 633-636 다인 1995 Royal College of Ophthalmologists 


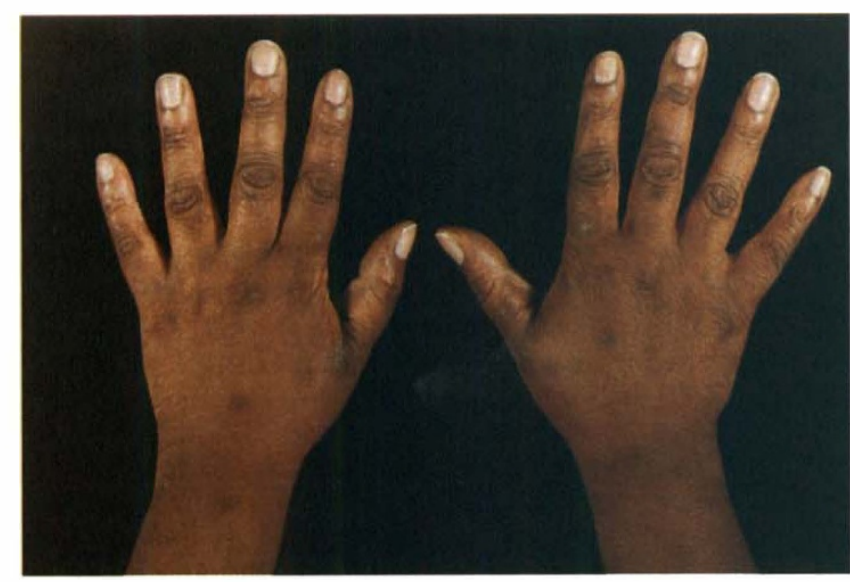

(a)

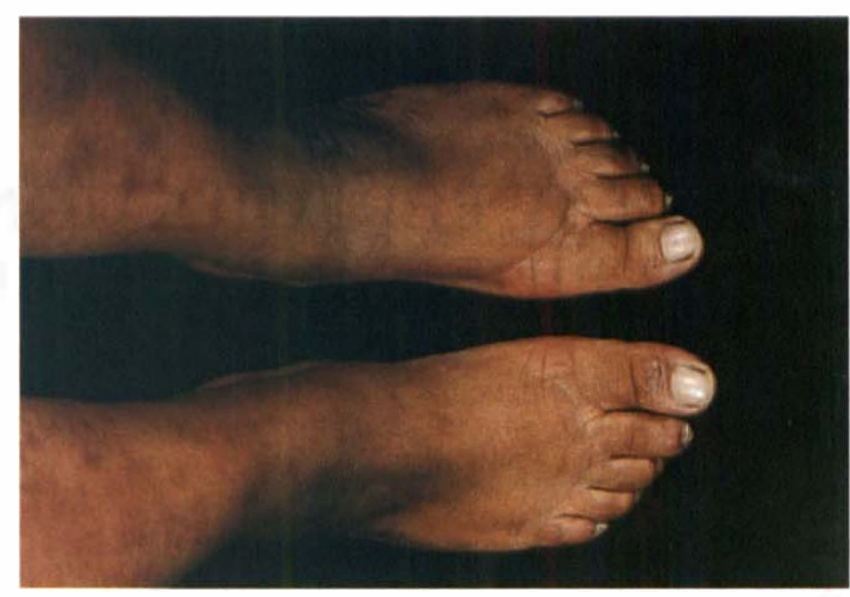

(b)

Fig. 3. Scars on dorsum of hands (a) and feet (b).

blurring of the vision and the irritation responded well initially to topical lubricants.

A corneal infiltrate with only mild stromal thinning and without an overlying confluent epithelial defect developed in the nasal periphery of the left cornea. There was a segmental limbitis and scleritis adjacent to the affected area. The anterior chamber was quiet. In view of the previous problems with systemic steroids, and as she was already on azathioprine 250 $\mathrm{mg}$ daily, only topical steroids were added. The infiltrate cleared and the topical steroids were tailed off, but 4 weeks later a corneal perforation occurred at the same site. The cornea was cloudy and the left visual acuity was reduced to counting fingers. The anterior chamber was flat peripherally and very shallow centrally with iris plugging the corneal defect. A bandage contact lens was positioned and topical and systemic antibiotics were commenced. Topical mydriatics were also used initially. Intravenous methylprednisolone $(1 \mathrm{~g})$ was administered. Two days later the area of corneal thinning was more limited. The anterior chamber was deeper but the iris was still adherent to the cornea and peripheral anterior synechiae were developing elsewhere. The mydriatics were stopped and pilocarpine $4 \%$ drops were started. This succeeded in breaking the anterior synechiae including, surprisingly, that to the site of the corneal perforation. The bandage contact lens was removed. Seidel test was negative and the perforation remained well sealed. The cornea cleared gradually over the following few days and the scar started to become vascularised (Figs. 1, 2). The visual acuity returned to 6/18 unaided, and could be corrected to 6/6. The associated scleritis was also settling. A second bolus dose of $1 \mathrm{~g}$ methylprednisolone was administered 5 days after the initial injection. Oral prednisolone 10 $\mathrm{mg}$ daily was commenced and appeared to be well tolerated by the patient. The steroids were tailed off over a few weeks. Within a month only topical lubricants were needed. During the following year the corneal scar became more vascularised and there has been no recurrence of the scleritis or the corneal melting. The corrected visual acuity remains $6 / 6$ in each eye.

\section{DISCUSSION}

EBA is a rare non-inflammatory condition, predominantly adult in onset, thought to affect females and blacks more commonly. There is no family history and the blisters arise classically as a result of trauma on the dorsum of hands, feet, elbows and knees. Linear atrophic scars and milia are common. ${ }^{9,10}$ Nail dystrophy and scarring alopecia may be seen.

There is known to be an increased frequency of class II HLA-DR2 haplotype in those patients. ${ }^{10}$ The characteristic histopathological and immunological features include linear deposits of $\mathrm{IgG}$ at the basement membrane zone (BMZ) and IgG deposits beneath the lamina densa recognised by immunoelectron microscopy; circulating $\mathrm{IgG}$ anti-BMZ antibodies are found in two-thirds of patients some time in their disease. . $^{3,10-13}$

Mucous membrane involvement is seen in $50 \%$ of cases. $5,7,8,14$ The systemic manifestations respond poorly to therapeutic measures. ${ }^{15}$ High-dose corticosteroids (prednisolone $1-2 \mathrm{mg} / \mathrm{kg}$ body weight), cyclophosphamide, azathioprine and methotrexate have all been used without much success. Dapsone has been found to be of little benefit either in conjunction with or without steroids. ${ }^{16}$ Cyclosporin A has been more successful in some patients who failed to respond to other lines of treatment. ${ }^{17,18}$ Plasmapheresis has been performed in some cases. ${ }^{19}$

The association of EBA and sarcoidosis has not been previously reported but many systemic diseases $^{20-23}$ including rheumatoid arthritis, inflammatory bowel disease and thyroiditis have been 
associated with EBA, suggesting a possible common autoimmune aetiology.

The ocular manifestations of EBA reported so far $^{5-7}$ include conjunctival and corneal scarring, symblepharon. and 'blindness'.5,7 However, the diagnosis of EBA was not confirmed in all cases. Some patients appear to have developed the changes more typical of pemphigoid, with subepithelial scarring and fibrosis leading to symblepharon formation and eventually corneal problems due to exposure. ${ }^{24}$ Only one reported patient ${ }^{5}$ with a proven diagnosis of EBA has developed corneal perforation, and in common with our patient she did not have significant conjunctival scarring, but her response to treatment was poor and she eventually required a therapeutic keratoplasty.

The patient we report had sarcoidosis and went on to develop blisters which left her with scars on her hands and feet (Fig. 3). Her HLA DR subtype (14 and 15) is consistent with DR2 haplotype. A split skin biopsy was performed. Sections of markedly hyperkeratotic skin showed a subepidermal bullous lesion. Some regenerating epidermal keratinocytes were seen in the base of the bulla. No eosinophils or other inflammatory cells were seen. Immunofluorescent and immunoperoxidase studies were performed, the latter using the pronase technique. Linear deposition of $\mathrm{IgG}$ and C3 at the epidermodermal junction was demonstrated which supports a diagnosis of EBA. Our patient had dry eyes but did not have the diffuse conjunctival scarring seen in other bullous conditions. She developed a corneal infiltrate without significant melting. She was on systemic azathioprine and the addition of topical steroids appeared to help initially, but she went on to develop a corneal perforation. Topical steroids are sometimes useful in the management of sterile marginal corneal ulcers with an infiltrative component $^{25}$ and their use (with caution) for EBA has been advocated, ${ }^{26}$ but the risks of perforation are well documented. $^{27}$ Marginal corneal ulceration and melting occur in a number of autoimmune and vasculitic conditions, but are not a typical feature of sarcoidosis and are therefore more likely to have been a manifestation of EBA. The exact pathogenesis of these lesions is unclear but may involve local ischaemia or collagenase production. This might be the underlying mechanism in our patient, who had no confluent epithelial defect or signs of infection and only a localised segment of scleritis. A regime of 'pulsed' intravenous steroids as recommended for other types of peripheral corneal melting ${ }^{28}$ has resulted in a satisfactory anatomical and visual outcome.

\section{CONCLUSION}

The availability of specific tests and criteria for the diagnosis of EBA provides an opportunity for more accurate assessment of its ocular manifestations and the recognition of signs specific to this recently better identified entity. It is important to appreciate the potential visual morbidity, even in eyes that do not show the diffuse type of scarring seen in other cicatricial bullous diseases. The use of pulsed steroid treatment may be worth considering.

Key words: Corneal melting, Corneal perforation, Epidermolysis bullosa acquisition, Pulsed steroid, Sarcoidosis.

\section{REFERENCES}

1. Krivo JM, Miller F. Immunopathology of epidermolysis bullosa acquisita: association with mixed cryoglobulinemia. Arch Dermatol 1978;114:1218-20.

2. Nicboer C, Boorsma DM, Woerdman MJ, Kalsbeek GL. Epidermolysis bullosa acquisita: immunofluorescence, electron microscopic and immunoelectron microscopic studies in four patients. $\mathrm{Br} \mathrm{J}$ Dermatol 1980;102:383-92.

3. Woodley DT, Briggaman RA, O'Keefe EJ, et al. Identification of the skin basement membrane autoantigen in epidermolysis bullosa acquisita. $\mathbf{N}$ Engl $\mathbf{J}$ Med 1984;310:1007-13.

4. McDonnell PJ, Spalton DJ. The ocular signs and complications of epidermolysis bullosa. J R Soc Med 1988;81:576-8.

5. Lang PJ Jr, Tapert MJ. Severe ocular involvement in a patient with epidermolysis bullosa acquisita. J'Am Acad Dermatol 1987;16:439-43.

6. Richter BJ, McNutt S. The spectrum of epidermolysis bullosa acquisita. Arch Dermatol 1979;115:1325-8.

7. Palestine RF, Kossard S, Dicken CH. Epidermolysis bullosa acquisita: a heterogenous disease. J Am Acad Dermatol 1981;5:43-53.

8. Dahl MGC. Epidermolysis bullosa acquisita: a sign of cicatricial pemphigoid? $\mathrm{Br} \mathrm{J}$ Dermatol 1979;101: 475-84.

9. Rocnigk HH Jr, Ryan JG, Bergfeld WF. Epidermolysis bullosa acquisita: report of three cases and review of all published cases. Arch Dermatol 1971;103:1-10.

10. Gammon WR, Heise ER, Burke WA, et al. Increased frequencies of HLA-DR2 in patients with autoantibodies to epidermolysis bullosa acquisita antigen: evidence that autoimmunity to type VII collagen is HLA class II allele associated. J Invest Dermatol 1988; 91:228-32.

11. Gammon WR, Woodley WT, Dole KC, et al. Evidence that anti-basement membrane zone antibodies in bullous eruption of systemic lupus erythematosus recognise epidermolysis bullosa acquisita autoantigen. J Invest Dermatol 1985;84:502-11.

12. Gibbs RB, Minus HR. Epidermolysis bullosa acquisita with electron microscopical studies. Arch Dermatol 1975;111:215-20.

13. Yaoita H, Briggaman RA, Lawley TJ, et al. Epidermolysis bullosa acquisita: ultrastructural and immunological studies. J Invest Dermatol 1981;76:288-92.

14. Nilsen R, Livden J, Thunold S. Oral lesions of epidermolysis bullosa acquisita. Oral Surg 1978;45: 749-54.

15. Briggaman RA, Gammon WR, Woodley DT. Epidermolysis bullosa acquisita of the immunopathological type (dermolytic pemphigoid). J Invest Dermatol 1985;85:79s-84s.

16. Barton DD, Fine JD, Gammon WR, Sams WM Jr. 
Bullous systemic lupus erythematosus: an unusual clinical course and detectable circulating autoantibodies to the epidermolysis bullosa acquisita antigen. $\mathbf{J}$ Am Acad Dermatol 1986;15:369-73.

17. Connolly SM, Sander HM. Treatment of epidermolysis bullosa acquisita with cyclosporine. J Am Acad Dermatol 1987;16:890.

18. Zachariae H. Cyclosporin A in epidermolysis bullosa acquisita. J Am Acad Dermatol 1987;17:1058-9.

19. Furue M, Iwata M, Yoon HI, et al. Epidermolysis bullosa acquisita: clinical response to plasma exchange therapy and circulating anti-basement membrane zone antibody titer. J Am Acad Dermatol 1986;14:873-8.

20. Livden JK, Nilsen R, Thunold S, Schjonsby $H$. Epidermolysis bullosa acquisita and Crohn's disease. Acta Dermatovenereol (Stockh)1978;58:241-4.

21. Ray TL, Levine JB, Weiss W, Ward PA. Epidermolysis bullosa acquisita and inflammatory bowel disease. J Am Acad Dermatol 1982;6:242-52.

22. Raab B, Fretzin D, Bronson D, et al. Epidermolysis bullosa acquisita and inflammatory bowel disease. JAMA 1983;25:1746-8.
23. Burke WA, Briggaman RA, Gammon WR. Epidermolysis bullosa acquisita in a patient with multiple endocrinopathies syndrome. Arch Dermatol 1986;122: 187-9.

24. Wright P. Enigma of ocular cicatricial pemphigoid: a comparative study of clinical and immunological findings. Trans Ophthalmol Soc UK 1979;99:141-5.

25. Gardner KM, Rajacich GM, Mondino BJ. Ophthalmological manifestations of adult rheumatoid arthritis and cicatricial pemphigoid. Int Ophthalmol Clin 1985;25:1.

26. Smith RE, Schanzlin DJ. Rheumatoid diseases. In: The cornea: scientific foundations and clinical practice, 2nd ed. Boston/Toronto: Little, Brown, 1983:327-44.

27. Watson PG. Disease of sclera and episclera. In: Duane T, editor. Clinical ophthalmology, vol 4. Hagerstown, MD: Harper \& Row, 1980:1-39.

28. Meyer PAR, Watson PG, Franks W, Dubord P. 'Pulsed' immunosuppressive therapy in the treatment of immunologically induced corneal and scleral disease. Eye 1987;1:487-95. 